\title{
Aurora kinases as an anti-cancer target
}

Takayuki Ikezoe

Department of Hematology and Respiratory Medicine, Kochi University, Nankoku, Kochi 783-8505, Japan

*Address correspondence: Takayuki Ikezoe, MD

Department of Hematology and Respiratory Medicine, Kochi University

Nankoku, Kochi 783-8505, Japan

Tel: +81-88-880-2345, Fax: +81-88-880-2348, e-mail: ikezoet@kochi-u.ac.jp

\begin{abstract}
The Aurora family of serine/threonine kinases plays an important role in chromosome alignment, segregation and cytokinesis during mitosis. Recent studies have found aberrant expression of Aurora kinases in a variety of human solid tumors and hematological malignancies, suggesting they have a role in carcinogenesis. This review highlights the function of Aurora kinases in the regulation of mitosis and presents the rationale for these kinases as an anti-cancer target. We also review recently developed inhibitors of Aurora kinases.
\end{abstract}

Key words. Aurora kinase; cancer; leukemia; mitosis.

\section{Introduction}


The Aurora family of serine/threonine kinases plays an important role in chromosome alignment, segregation and cytokinesis during mitosis. The family has three members: Aurora A, B and C, which share 67-76\% amino acid sequence identity in their catalytic domains, but show little $\mathrm{N}$-terminus similarity $[1,2]$. Aurora A localizes on centrosomes and has a crucial role in each step of mitosis [2]. Aurora B is a chromosomal passenger protein that localizes at centromeres during the prometaphase and subsequently relocates to midzone microtubules and midbodies during anaphase and telophase $[1,3]$. Aurora B is involved in chromosome alignment, kinetochore-microtubule biorientation, activation of the spindle assembly checkpoint and cytokinesis $[1,3]$. Aurora $\mathrm{C}$ is specifically expressed in the testis and plays a role in spermatogenesis [4]. It was recently found that Aurora $\mathrm{C}$ also acts as a chromosomal passenger protein and might compensate for lost Aurora B function [5].

Aurora A and B are overexpressed in a variety of solid tumors, including those from colon [6,7], breast [7-10], prostate [11], pancreas [12], thyroid [13], and head and neck [14]. In addition, it has been found recently that Aurora A and B are aberrantly expressed in hematological malignancies including acute myelogenous leukemia (AML), chronic myelogenous leukemia (CML), and acute lymphoblastic leukemia (ALL) [15]. The significance of aberrant expression of Aurora kinases remains elusive, although high levels are associated with advanced clinical stage and poor prognosis in individuals with colorectal [7] and prostate [11] cancers and head and neck squamous-cell carcinoma [14]. Other studies have found aberrant expression of Aurora A kinase in early stage breast and ovarian cancers $[16,17]$. Examination of the relationship between Aurora $\mathrm{C}$ and cancer is limited; however several studies have found aberrant expression of Aurora $\mathrm{C}$ in colorectal, breast, and prostate cancers $[5,18]$. 
These observations suggest that Aurora kinases might be a promising molecular target for cancer treatment. A number of small-molecule inhibitors targeting Aurora kinases have been developed, which include MK0457 (formerly VX-680) [19], AZD1152 [20-22], MLN8054 [23], and PHA-739358 [24]. These compounds showed anti-tumor activity in preclinical studies and clinical trials are ongoing in the United States and Europe.

\section{Biological function of Aurora kinases.}

Aurora A. Aurora A is expressed widely in proliferating normal tissues, with expression being highest at the $\mathrm{G} 2 / \mathrm{M}$ phase of the cell cycle; levels are then rapidly decreased by degradation via the ubiquitin-proteasome pathway [25,26]. Aurora A localizes on duplicated centrosomes from the end of S phase to the beginning of the following G1 phase and plays a crucial role in each step of mitosis. For example, it regulates the maturation of centrosomes by interacting with transforming acid coiled-coil (TACC) proteins; activated TACC is recruited to the centrosome and forms a complex with microtubule-associated proteins such as Msps/XMAP215, centrosomin, and $\gamma$-tubulin, leading to growth of microtubules, which consequently promote maturation of the centrosome [Fig 1A, 27-31].

Aurora A also regulates mitotic entry by interacting with Ajuba, a LIM protein [32]: the phosphorylated form of Ajuba binds to Aurora A, leading to activation of Aurora A at late G2 phase. Interaction of Ajuba and Aurora A is essential for recruitment of the cyclin B1/CDK1 complex to the centrosome, where it becomes activated and commits cells to mitosis [Fig 1B, 32]. 
Aurora B. Aurora B is also widely expressed in proliferating normal cells with maximum expression at the G2/M phase of the cell cycle [33]. Similar to Aurora A kinase, levels of Aurora B protein are regulated by proteasomal degradation [34]. Aurora B kinase belongs to the chromosome passenger protein family, which comprises inner centrosome protein (INCENP), survivin, and borealin [35]. These proteins form a chromosome passenger complex and localize on the kinetochores from the prophase to the metaphase and on the central spindle and the midbody in cytokinesis [1]. Aurora B is activated by autophosphorylation after association with the passenger complex [36-40]. Inhibition of Aurora B by RNA interference showed that it is required for cytokinesis [41], where its important function is regulation of the kinesin-like protein pavarotti, which is essential for establishment of the central spindle during anaphase [Fig 2A]. Disruption of Aurora B caused mis-localization of pavarotti, resulting in cytokinesis defect [42]. Cytoskeletal proteins in the cleavage furrow, such as myosin II regulatory light chain, vimentin, desmin and glial fibrillary acidic protein, are also substrates of Aurora B and participate in filament formation and cytokinesis [43-45]. Other functions of Aurora B relate to histone modification: it phophorylates histone $\mathrm{H} 3$ on Ser10 [41] and Ser28 [46], and centromere protein A on Ser7 [47]. Phosphorylation of histone $\mathrm{H} 3$ on Ser10 dissociates heterochromatin protein 1 (HP1) from heterochromatin at the onset of mitosis [48]; however, the biological effect of HP1 release remains unknown.

Aurora B is also implicated in microtubule-kinetochore attachment by interacting with the kinetochore-specific histone H3 variant CENP-A [Fig 2B, 49]. CENP-A is first phosphorylated on Ser7 by Aurora A during the prophase, recruiting Aurora B to the inner centromere [50]. Aurora B then maintains phosphorylation of CENP-A on Ser7 
from late prophase through metaphase and regulates kinetochore functions [50].

Other Aurora B substrates include BubR1 and Mad2, mitotic checkpoint proteins. Inhibition of Aurora B by RNA interference compromised the mitotic checkpoint, resulting in increased numbers of aneuploid cells [51].

Aurora C. Aurora C is a much less extensively studied member of the Aurora kinase family. Aurora $\mathrm{C}$ is localized to $\mathrm{Chr} 19 \mathrm{q} 13$ and was first isolated from a testis cDNA library [52]. Aurora $\mathrm{C}$ is specifically expressed in testis, as measured by northern blot analysis, and is believed to play an important role in spermatogenesis [4]. Recent studies found that Aurora $\mathrm{C}$ is also a chromosomal passenger protein and binds to INCENP, for which it has lower affinity than Aurora B [5]. In addition, forced expression of Aurora $\mathrm{C}$ rescued an Aurora-B-silenced phenotype of HeLa cells in vitro, suggesting that Aurora $\mathrm{C}$ might be able to compensate for lost Aurora B function [5].

\section{Aurora kinases and cancer.}

Aurora A. Aurora A is located on chromosome 20q13.2, a region commonly amplified in human malignancies, including those from colon, breast, pancreas, ovary, and prostate $[6,7]$. Although aberrant expression of Aurora A has been found in various tumor types, it does not always correlate with gene amplification. For example, amplification of Aurora A was found in only 3\% of hepatocellular carcinomas (HCCs), although more than $60 \%$ of HCCs overexpressed Aurora A [53], suggesting that mechanisms other than gene amplification may contribute to the aberrant expression. Forced expression of Aurora A gene in murine NIH $3 \mathrm{~T} 3$ cells induced abnormal centrosome number (amplification) and transformation in vitro [54]. In addition, forced 
expression of Aurora A in near diploid human breast epithelial cells induced similar centrosome abnormality, as well as induction of aneuploidy [7]. Other groups also found that conditional expression of Aurora A in murine mammary epithelium induced accumulation of binucleated cells and transformation when p53 was deleted [55]. These findings suggest that Aurora A can act as an oncogene.

Interestingly, Aurora A interacts with and inactivates the tumor suppressor p53; Aurora A phosphorylates p53 on Ser315, facilitating MDM-2-mediated degradation of p53 in cancer cell lines [56]. Aurora A phosphorylates p53 on Ser215 and abrogates its DNA-binding ability, resulting in inhibited transcriptional activity [57]. Aurora A also interacts with the breast cancer susceptibility gene BRCA 1. Aurora A colocalizes with BRCA 1 in centrosomes and phophorylates BRCA 1 on Ser308, leading to impairment of its function as a G2/M checkpoint keeper [58]. Thus, it may also be involved in the carcinogenesis of breast cancer.

Overexpression of Aurora A causes resistance to Taxol-mediated apoptosis in cancer cells. Taxol, a tubulin depolymerizing agent, activates the spindle checkpoint in HeLa cells, but this is overridden by Aurora A, resulting in escape from apoptosis [59].

Aurora B. The contribution of Aurora B to carcinogenesis has been less studied than that of Aurora A. Aurora B is located on chromosome 17p13.1, a region not typically amplified in human malignancies; however, overexpression of Aurora kinase B has been shown in a variety of human cancers, including glioblastoma multiforme [60], malignant mesothelioma [61], and hematological malignancies [15]. High levels of Aurora B are associated with adverse clinical outcomes in patients with endometrial carcinoma [62]. Forced expression of Aurora B in Chinese hamster embryo cells 
resulted in chromosome instability and increased tumor invasiveness in association with constitutive expression of phosphorylated (p)-histone H3 on Ser10 [63], suggesting that Aurora B can act as an oncogene.

Aurora C. The involvement of Aurora C in carcinogenesis has been the least explored of all the Aurora kinase family. The few available studies found that Aurora $\mathrm{C}$ was overexpressed in colorectal, breast, and prostate cancers $[5,18]$. The level of expression of Aurora $\mathrm{C}$ correlated with the degree of dysplastic change in colorectal cancer cells [18]. Forced expression of Aurora C in HeLA cells produced polyploidy, which was augmented by inactivation of p53 [64]. These observations suggest that Aurora C might be a promising molecular target for cancer treatment.

4. Development of Aurora kinase inhibitors. Evidence linking Aurora kinases to malignancies has raised the possibility of targeting these kinases for cancer therapy. A number of small-molecule inhibitors with activity against Aurora A and/or B have been developed. The first generation of this class of compound included Hesperadin, ZM447439, and MK0457 (formally VX-680). The next generation of Aurora kinase inhibitor has been developed and includes AZD1152, a potent and selective inhibitor of Aurora B kinase; MLN8054, an orally available selective inhibitor of Aurora A kinase; and the pan-Aurora kinase inhibitor PHA-739358. Some of these agents are undergoing evaluation in clinical trials.

Hesperadin. Hesperdin (Boehringer Ingelheim) is a novel indolinone with specific activity against Aurora $\mathrm{B}$ kinase, as it was shown to inhibit $\mathrm{p}$-histone $\mathrm{H} 3$ with an $\mathrm{IC}_{50}$ of $250 \mathrm{nM}$. It was the first proven inhibitor of Aurora kinase B, but has not been verified in 
clinical trials. Hesperadin induced polyploidy in HeLa cells [Table 1, 65].

ZM447439. ZM447439 (AstraZeneca) is an ATP-competitive selective inhibitor of Aurora kinase A and $\mathrm{B}$ ( $\mathrm{IC}_{50} 110 \mathrm{nM}$ and $130 \mathrm{nM}$ for Aurora $\mathrm{A}$ and $\mathrm{B}$, respectively), which compromises chromosomal alignment and cell division as well as mitotic checkpoint in HeLa, A549, MCF-7 and DLD1 cells [Table 1, 51]. The phenotypes induced by ZD447439 were due to Aurora B inhibition, as determined by RNA interference experiments [51]. In addition, a recent study found that ZM447439 was active against hematological malignancies including AML and Philadelphia chromosome-positive ALL [15]. This study also found that cells expressing wild-type p53 were more sensitive to ZM447439-mediated growth inhibition than cells possessing the mutated p53 gene. These observations suggest that the p53-dependent post-mitotic checkpoint played an important role in Aurora kinase inhibitor-mediated apoptosis. ZM447439 has not been developed in clinical trials.

MK0457. MK0457 (VX-680; Merk/Vertex) is an ATP-competitive pan-Aurora kinase inhibitor ( $\mathrm{IC}_{50} 0.6,18$, and $4.6 \mathrm{nM}$ for Aurora A, B, and C, respectively) [Table 1, 19]. In vitro study showed that MK0457 induced endoreduplication in cancer cells, a characteristic feature of phenotype mediated by inhibition of Aurora B kinase by RNA interference. Preclinical study showed that MK0457 inhibited proliferation of human myelogenous leukemia HL60 and colon cancer HCT116 cells in a murine xenograft model [19]. MK0457 effectively inhibited colony formation of freshly isolated AML cells with internal tandem duplication mutations in the fms-like tyrosine kinase (FLT3) gene [19]. MK0457 possesses many off-targets including FLT3 kinase. Interestingly, MK0457 was able to inhibit imatinib- or dasatinib-resistant ABL kinase mediated by T315I mutation [66]. A recent clinical study showed that MK0457 was active in 
individuals with imatinib-resistant CML or ALL patients possessing T315I-BCR/ABL mutation [66]. A phase 1 clinical trial of MK0457 in 22 heavily pre-treated patients found a recommended dose of $10 \mathrm{mg} / \mathrm{m} / \mathrm{h}$, continuous $24 \mathrm{~h}$ infusion for 5 days every 28 days. Neutropenia was the dose-limiting toxicity. One patient with pancreatic cancer and another with non-small-cell lung cancer achieved stable disease as their best response, which lasted over 6 months [67].

AZD1152. AZD1152 (AstraZeneca) is a novel acetanilide-substituted pyrazole-aminoquinazoline prodrug that is converted rapidly to the active drug AZD1152 hydroxy-QPA (AZD1152-HQPA) in human plasma [20]. AZD1152-HQPA is a specific and selective inhibitor of the enzymatic activity of Aurora B kinase $\left(\mathrm{IC}_{50} 0.37\right.$ $\mathrm{nM}$ versus $1368 \mathrm{nM}$ for Aurora B and A kinases, respectively); the inhibitor had even lower activity against a panel of more than 50 other serine-threonine and tyrosine kinases including FLT3, JAK2, and ABL [Table 1, 20,22]. Preclinical studies showed that AZD1152 was active against a variety of solid tumors including colon, breast, and lung cancers, as well as myelogenous leukemia in a tumor xenograft model [21,22]. These studies demonstrated phosphorylated-histone H3 as a biomarker of Aurora inhibition. Of note, AZD1152 potentiated the anti-tumor effects of the tubulin depolymerizing agent vincristine and the topoisomerase II inhibitor daunorubicin in AML cells in vitro and in vivo [22]. In addition, AZD1152 was able to inhibit the proliferation of imatinib-resistant ALL cells with Philadelphia chromosome, although it was not active against BCR/ABL [22].

A recent Phase 1 trial of AZD1152 in 19 patients showed that the maximum tolerated dose was $200 \mathrm{mg}$, given as a 2-h weekly infusion. As with MK0457, neutropenia was the dose-limiting toxicity. Stable disease for longer than 25 weeks was 
the best response achieved in three patients (one with melanoma, one with nasopharyngeal carcinoma and one with adenoid cystic carcinoma) [68].

MLN8054. MLN8054 is an orally available, potent and selective inhibitor of Aurora A kinase ( $\mathrm{IC}_{50} 4 \mathrm{nM}$ versus $172 \mathrm{nM}$ for Aurora A and B kinase, respectively) [Table 1, 23]. Exposure of cells to low concentrations of MLN8054 induced abnormal mitotic spindle formation and chromosomal alignment defects, characteristics of Aurora A inhibition; however, downregulation of p-histone H3 was shown on exposure to higher concentrations, consistent with Aurora B inhibition. MLN8054 is currently being evaluated in a phase 1 trial for patients with advanced solid tumors.

PHA-739358. PHA-739358 (Nerviano Medical Sciences) is an ATP-competitive pan-Aurora kinase inhibitor $\left(\mathrm{IC}_{50} \mathrm{~s}\right.$ of 13,79 , and $61 \mathrm{nM}$ for Aurora $\mathrm{A}, \mathrm{B}$, and $\mathrm{C}$, respectively) [Table 1, 24]. As with MLN8054, phenotypic changes in cells shift from Aurora A to Aurora B inhibition on exposure to higher concentrations of the agent. PHA-739358 showed significant cross-reactivity with ABL in a biochemical assay, with an $\mathrm{IC}_{50}$ of $25 \mathrm{nM}$ [24]. Notably, PHA-739358 was active against T315I BCR/ABL mutation [69]. PHA-739358 is currently being evaluated in clinical trials in solid and hematological malignancies, including imatinib-resistant CML.

Thus, the inhibitors of Aurora kinase activity are well tolerated and produce some clinical benefits. Preclinical studies have found that inhibition of Aurora kinase A and B sensitizes malignant cells to apoptosis mediated by tubulin depolymerizing agents $[22,59]$. Clinical trials are warranted to evaluate the efficacy of combining Aurora kinase inhibitor and this class of chemotherapeutic agents.

5. Conclusions. Recent elucidation of the biological function of Aurora kinases in 
normal and cancer cells has led to the development of small-molecule inhibitors.

Preclinical as well as preliminary results of clinical trials suggest that this class of agent is promising for cancer treatment, although the molecular mechanisms by which inhibitors of Aurora kinases induce the growth arrest and apoptosis of cancer cells remain to be fully elucidated. Also, several issues concerning this class of agent have not been addressed: for example, it is not known which Aurora kinase is the best target for cancer treatment. Further studies are clearly required to incorporate this class of agent in the future treatment strategy for cancer.

Acknowledgment. This work was supported in part by the Fund for Academic Research from Kochi University. 


\section{References.}

1. M. Carmena, W.C. Earnshaw, The cellular geography of aurora kinases, Nat Rev Mol Cell Biol. 4 (2003)842-54.

2. T. Marumoto, D. Zhang, H. Saya, Aurora A-a guardian of poles, Nat Rev Cancer. $5(2005) 42-50$.

3. M. Kimura, Y. Matsuda, T. Yoshioka, N. Sumi, Y. Okano, Identification and characterization of STK12/Aik2: a human gene related to aurora of Drosphila and yeast IPL1, Cytogenet Cell Genet. 82(1998)147-52.

4. C.J. Tang, C.Y. Lin, T.K. Tang, Dynamic localization and functional implications of Aurora-C kinase during male mouse meiosis, Dev Biol. 290(2006)398-410.

5. K. Sasai, H. Katayama, D.L. Stenoien, S. Fujii, R. Honda, M. Kimura, Y. Okano, M. Tatsuka, F. Suzuki, E.A. Nigg, et al, Aurora-C kinase is a novel chromosomal passenger protein that can complement Aurora-B kinase function in mitotic cells. Cell Motil Cytoskeleton. 59(2004)249-63.

6. J.R. Bischoff, L. Anderson, Y. Zhu, K. Mossie, L. Ng, B. Souza, B. Schryver, P. Flanagan, F. Clairvoyant, C. Ginther, et al, A homologue of Drosophila aurora kinase is oncogenic and amplified in human colorectal cancers, EMBO J. 17(1998)3052-65.

7. H. Zhou, J. Kuang, L. Zhong, W.L. Kuo, J.W. Gray, A. Sahin, B.R. Brinkley, S. Sen, Tumour amplified kinase STK15/BTAK induces centrosome amplification, aneuploidy and transformation, Nat Genet. 20(1998)189-93.

8. M.E. Royce, W. Xia, A.A. Sahin, H. Katayama, D.A. Johnston, G. Hortobagyi, S. Sen, M.C. Hung, STK15/Aurora-A expression in primary breast tumors is correlated with nuclear grade but not with prognosis, Cancer. 100(2004)12-9.

9. S. Sen, H. Zhou, R.A. White, A putative serine/threonine kinase encoding gene BTAK on 
chromosome 20q13 is amplified and overexpressed in human breast cancer cell lines, Oncogene. 14(1997)2195-200.

10. T. Tanaka, M. Kimura, K. Matsunaga, D. Fukada, H. Mori, Y. Okano, Centrosomal kinase AIK1 is overexpressed in invasive ductal carcinoma of the breast, Cancer Res. 59(1999)2041-4.

11. P. Chieffi, L. Cozzolino, A. Kisslinger, S. Libertini, S. Staibano, G. Mansueto, G. De Rosa, A. Villacci, M. Vitale, S. Linardopoulos, et al, Aurora B expression directly correlates with prostate cancer malignancy and influence prostate cell proliferation, Prostate. 66(2006)326-33.

12. D. Li, J. Zhu, P.F. Firozi, J.L. Abbruzzese, D.B. Evans, K. Cleary, H. Friess, S. Sen, Overexpression of oncogenic STK15/BTAK/Aurora A kinase in human pancreatic cancer. Clin Cancer Res. 9(2003)991-7.

13. S. Ulisse, J.G. Delcros, E. Baldini, M. Toller, F. Curcio, L. Giacomelli, C. Prigent, F.S. Ambesi-Impiombato, M. D'Armiento, Y. Arlot-Bonnemain, Expression of Aurora kinases in human thyroid carcinoma cell lines and tissues, Int J Cancer. 119(2006)275-82.

14. R. Reiter, P. Gais, U. Jutting, M.K. Steuer-Vogt, A. Pickhard, K. Bink, S. Rauser, S. Lassmann, H. Höfler, M. Werner, et al, Aurora kinase a messenger RNA overexpression is correlated with tumor progression and shortened survival in head and neck squamous cell carcinoma, Clin Cancer Res. 12(2006)5136-41.

15. T. Ikezoe, Y. Jing, C. Nishioka, T. Tasaka, A. Taniguchi, Y. Kuwayama, N. Komatsu, K. Bandobashi, K. Togitani, H.P. Koeffler, H. Taguchi. A novel treatment strategy targeting Aurora kinases in acute myelogenous leukemia, Mol Cancer Ther. 6(2007)1851-7. 
16. T.M. Goepfert, Y.E. Adigun, L. Zhong, J. Gay, D. Medina, W.R. Brinkley, Centrosome amplification and overexpression of aurora A are early events in rat mammary carcinogenesis. Cancer Res. 62(2002)4115-22.

17. T.M. Gritsko, D. Coppola, J.E. Paciga, L. Yang, M. Sun, S.A.Shelley, J.V. Fiorica, S.V. Nicosia, J.Q. Cheng. Activation and overexpression of centrosome kinase BTAK/Aurora-A in human ovarian cancer. Clin Cancer Res. 9(2003)1420-6.

18. T. Takahashi, M. Futamura, N. Yoshimi, J. Sano, M. Katada, Y. Takagi, M. Kimura, T. Yoshioka, Y. Okano, S. Saji. Centrosomal kinases, HsAIRK1 and HsAIRK3, are overexpressed in primary colorectal cancers. Jpn J Cancer Res. 91(2000)1007-14.

19. E.A.Harrington, D. Bebbington, J. Moore, R.K. Rasmussen, A.Q. Ajose-Adeogun, T. Nakayama, J.A. Graham, C. Demur, T. Hercend, A. Diu-Hercend, et al, VX-680, a potent and selective small-molecule inhibitor of the Aurora kinases, suppresses tumor growth in vivo. Nat Med. 10(2004)262-7.

20. A.A. Mortlock, K.M. Foote, N.M. Heron, F.H. Jung, G. Pasquet, J.J. Lohmann, N. Warin, F. Renaud, C. De Savi, N.J. Roberts, et al, Discovery, synthesis, and in vivo activity of a new class of pyrazoloquinazolines as selective inhibitors of aurora B kinase, J Med Chem. 50(2007)2213-24.

21. R.W. Wilkinson, R. Odedra, S.P. Heaton, S.R. Wedge, N.J. Keen, C. Crafter, J.R. Foster, M.C. Brady, A. Bigley, E. Brown, et al, AZD1152, a selective inhibitor of Aurora B kinase, inhibits human tumor xenograft growth by inducing apoptosis, Clin Cancer Res. 13(2007)3682-8.

22. J. Yang, T. Ikezoe, C. Nishioka, T. Tasaka, A. Taniguchi, Y. Kuwayama, N. Komatsu, K. Bandobashi, K. Togitani, H.P. Koeffler, et al, A. AZD1152, a novel and selective aurora B kinase inhibitor, induces growth arrest, apoptosis, and sensitization for tubulin 
depolymerizing agent or topoisomerase II inhibitor in human acute leukemia cells in vitro and in vivo. Blood. 110(2007)2034-40.

23. M.G. Manfredi, J.A. Ecsedy, K.A. Meetze, S.K. Balani, O. Burenkova, W. Chen, K.M. Galvin, K.M. Hoar, J.J. Huck, P.J. LeRoy, et al, Antitumor activity of MLN8054, an orally active small-molecule inhibitor of Aurora A kinase. Proc Natl Acad Sci U S A. 104(2007)4106-11.

24. D. Fancelli, J. Moll, M. Varasi, R. Bravo, R. Artico, D. Berta, S. Bindi, A. Cameron, I. Candiani, P. Cappella,et al, 1,4,5,6-Tetrahydropyrrolo[3,4-c]pyrazoles: identification of a potent aurora kinase inhibitor with a favorable antitumor kinase inhibition profile, J Med Chem. 49(2006)7247-51.

25. A. Castro, Y. Arlot-Bonnemains, S. Vigneron, J.C. Labbe, C. Prigent, T. Lorca, APC/Fizzy-Related targets Aurora-A kinase for proteolysis. EMBO Rep. 3(2002)457-62.

26. S. Taguchi, K. Honda, K. Sugiura, A. Yamaguchi, K. Furukawa, T. Urano, Degradation of human Aurora-A protein kinase is mediated by hCdh1, FEBS Lett. 519(2002)59-65

27. D. Berdnik, J.A. Knoblich, Drosophila Aurora-A is required for centrosome maturation and actin-dependent asymmetric protein localization during mitosis, Curr Biol. 12(2002)640-7.

28. R. Giet, D. McLean, S. Descamps, M.J. Lee, J.W. Raff, C. Prigent, D.M. Glover, Drosophila Aurora A kinase is required to localize D-TACC to centrosomes and to regulate astral microtubules, J Cell Biol. 156(2002)437-51.

29. C.A. Kemp, K.R. Kopish, P. Zipperlen, J. Ahringer, K.F. O'Connell, Centrosome maturation and duplication in C. elegans require the coiled-coil protein SPD-2, Dev Cell. 6(2004)511-23.

30. E. Hannak, M. Kirkham, A.A. Hyman, K. Oegema, Aurora-A kinase is required for 
centrosome maturation in Caenorhabditis elegans. J Cell Biol. 155(2001)1109-16.

31. Y. Terada, Y. Uetake, R. Kuriyama, Interaction of Aurora-A and centrosomin at the microtubule-nucleating site in Drosophila and mammalian cells,

J Cell Biol. 162(2003)757-63.

32. T. Hirota, N. Kunitoku, T. Sasayama, T. Marumoto, D. Zhang, M. Nitta, K. Hatakeyama, H. Saya, Aurora-A and an interacting activator, the LIM protein Ajuba, are required for mitotic commitment in human cells, Cell. 114(2003)585-98.

33. R.R. Adams, M. Carmena, W.C. Earnshaw, Chromosomal passengers and the (aurora) ABCs of mitosis, Trends Cell Biol, 11(2001)49-54.

34. F. Shu, S. Guo, Y. Dang, M, Qi, G. Zhou, Z. Guo, Y. Zhang, C. Wu, S. Zhao, L.Yu, Human aurora-B binds to a proteasome alpha-subunit $\mathrm{HC} 8$ and undergoes degradation in a proteasome-dependent manner, Mol Cell Biochem. 254(2003)157-62.

35. R.R. Adams, S.P. Wheatley, A.M. Gouldsworthy, S.E. Kandels-Lewis, M. Carmena, C. Smythe, D.L. Gerloff, W.C. Earnshaw, INCENP binds the Aurora-related kinase AIRK2 and is required to target it to chromosomes, the central spindle and cleavage furrow, Curr Biol. 10(2000)1075-8.

36. R. Gassmann, A. Carvalho, A.J. Henzing, S. Ruchaud, D.F. Hudson, R. Honda, E.A. Nigg, D.L. Gerloff, W.C. Earnshaw, Borealin: a novel chromosomal passenger required for stability of the bipolar mitotic spindle, J Cell Biol. 166(2004)179-91.

37. S.C. Sampath, R. Ohi, O. Leismann, A. Salic, A. Pozniakovski, H. Funabiki, The chromosomal passenger complex is required for chromatin-induced microtubule stabilization and spindle assembly, Cell. 118(2004)187-202.

38. E.K. Speliotes, A. Uren, D. Vaux, H.R. Horvitz, The survivin-like C. elegans BIR-1 protein acts with the Aurora-like kinase AIR-2 to affect chromosomes and the spindle 
midzone, Mol Cell. 6(2006)211-23.

39. J. Chen, S. Jin, S.K. Tahir, H. Zhang, X. Liu, A.V. Sarthy, T.P. McGonigal, Z. Liu, S.H. Rosenberg, S.C. Ng, Survivin enhances Aurora-B kinase activity and localizes Aurora-B in human cells, J Biol Chem. 278(2003)486-90.

40. S.P. Wheatley, A.J. Henzing, H. Dodson, W. Khaled, W.C. Earnshaw, Aurora-B phosphorylation in vitro identifies a residue of survivin that is essential for its localization and binding to inner centromere protein (INCENP) in vivo, J Biol Chem. 279(2004)5655-60.

41. R. Giet, D.M. Glover, Drosophila aurora B kinase is required for histone H3 phosphorylation and condensin recruitment during chromosome condensation and to organize the central spindle during cytokinesis, J Cell Biol. 152(2001)669-82.

42. A.F. Severson, D.R. Hamill, J.C. Carter, J. Schumacher, B. Bowerman, The aurora-related kinase AIR-2 recruits ZEN-4/CeMKLP1 to the mitotic spindle at metaphase and is required for cytokinesis, Curr Biol. 10(2000)1162-71.

43. M. Murata-Hori, K. Fumoto, Y. Fukuta, T. Iwasaki, A. Kikuchi, M. Tatsuka, H. Hosoya, Myosin II regulatory light chain as a novel substrate for AIM-1, an aurora/Ipl1p-related kinase from rat, J Biochem (Tokyo). 128(2000)903-7.

44. H. Goto, Y. Yasui, A. Kawajiri, E.A. Nigg, Y. Terada, M. Tatsuka, K. Nagata, M. Inagaki, Aurora-B regulates the cleavage furrow-specific vimentin phosphorylation in the cytokinetic process, J Biol Chem. 278(2003)8526-30.

45. A. Kawajiri, Y. Yasui, H. Goto, M. Tatsuka, M. Takahashi, K. Nagata, M. Inagaki, Functional significance of the specific sites phosphorylated in desmin at cleavage furrow: Aurora-B may phosphorylate and regulate type III intermediate filaments during cytokinesis coordinatedly with Rho-kinase, Mol Biol Cell. (2003)1489-500. 
46. H. Goto, Y. Yasui, E.A. Nigg, M. Inagaki, Aurora-B phosphorylates Histone H3 at serine28 with regard to the mitotic chromosome condensation, Genes Cells. 7(2002)11-7.

47. S.G. Zeitlin, R.D. Shelby, K.F. Sullivan. CENP-A is phosphorylated by Aurora B kinase and plays an unexpected role in completion of cytokinesis, J Cell Biol. 155(2001)1147-57.

48. T. Hirota, J.J. Lipp, B.H. Toh, J.M. Peters, Histone H3 serine 10 phosphorylation by Aurora B causes HP1 dissociation from heterochromatin. Nature. 438(2005)1176-80.

49. S.G. Zeitlin, R.D. Shelby, K.F, Sullivan, CENP-A is phosphorylated by Aurora B kinase and plays an unexpected role in completion of cytokinesis. J Cell Biol. 155(2001)1147-57.

50. N. Kunitoku, T. Sasayama, T. Marumoto, D. Zhang, S. Honda, O. Kobayashi, K. Hatakeyama, Y. Ushio, H. Saya, T. Hirota, CENP-A phosphorylation by Aurora-A in prophase is required for enrichment of Aurora-B at inner centromeres and for kinetochore function. Dev Cell. 5(2003)853-64.

51. C.J. Morrow, A. Tighe, V.L. Johnson, M.I. Scott, C. Ditchfield, S.S. Taylor, Bub1 and aurora B cooperate to maintain BubR1-mediated inhibition of APC/CCdc20, J Cell Sci. 118(2005)3639-52.

52. M. Bernard, P. Sanseau, C. Henry, A. Couturier, C. Prigent, Cloning of STK13, a third human protein kinase related to Drosophila aurora and budding yeast Ipl1 that maps on chromosome 19q13.3-ter. Genomics. 53(1998)406-9.

53. Y.M. Jeng, S.Y. Peng, C.Y. Lin, H.C. Hsu, Overexpression and amplification of Aurora-A in hepatocellular carcinoma, Clin Cancer Res. 10(2004)2065-71.

54. L.E. Littlepage, H. Wu, T. Andresson, J.K. Deanehan, L.T. Amundadottir, J.V. Ruderman, Identification of phosphorylated residues that affect the activity of the mitotic kinase 
Aurora-A, Proc Natl Acad Sci U S A. 99(2002)15440-5.

55. D. Zhang, T. Hirota, T. Marumoto, M. Shimizu, N. Kunitoku, T. Sasayama, Y. Arima, L. Feng, M. Suzuki, M. Takeya, H. Saya, Cre-loxP-controlled periodic Aurora-A overexpression induces mitotic abnormalities and hyperplasia in mammary glands of mouse models, Oncogene. 23(2004)8720-30.

56. Y. Miyoshi, K. Iwao, C. Egawa, S. Noguchi. Association of centrosomal kinase STK15/BTAK mRNA expression with chromosomal instability in human breast cancers. Int J Cancer. 92(2001)370-3.

57. Q. Liu, S. Kaneko, L. Yang, R.I. Feldman, S.V. Nicosia, J. Chen, J.Q. Chen, Aurora-A abrogation of p53 DNA binding and transactivation activity by phosphorylation of serine 215, J Biol Chem. 279(2004)52175-82.

58. M. Ouchi, N. Fujiuchi, K. Sasai, H. Katayama, Y.A. Minamishima, P.P. Ongusaha, C. Deng, S. Sen, S.W. Lee, T. Ouchi, BRCA1 phosphorylation by Aurora-A in the regulation of G2 to M transition. J Biol Chem.279(2004)19643-8.

59. S. Anand, S. Penrhyn-Lowe, A.R. Venkitaraman, AURORA-A amplification overrides the mitotic spindle assembly checkpoint, inducing resistance to Taxol. Cancer Cell. $3(2003) 51-62$.

60. W.F. Zeng, K. Navaratne, R.A. Prayson, R.J. Weil, Aurora B expression correlates with aggressive behaviour in glioblastoma multiforme, J Clin Pathol. 60(2007)218-21.

61. F. Lopez-Rios, S. Chuai, R. Flores, S. Shimizu, T. Ohno, K. Wakahara, P.B. Illei, S. Hussain, L. Krug, M.F. Zakowski, et al, . Global gene expression profiling of pleural mesotheliomas: overexpression of aurora kinases and P16/CDKN2A deletion as prognostic factors and critical evaluation of microarray-based prognostic prediction, Cancer Res. 66(2006)2970-9. 
62. M. Kurai, T. Shiozawa, H.C. Shih, T. Miyamoto, Y.Z. Feng, H. Kashima, A. Suzuki, I. Konishi, Expression of Aurora kinases A and B in normal, hyperplastic, and malignant human endometrium: Aurora B as a predictor for poor prognosis in endometrial carcinoma, Hum Pathol. 36(2005)1281-8.

63. T. Ota, S. Suto, H. Katayama, Z.B. Han, F. Suzuki, M. Maeda, M. Tanino, Y. Terada, M. Tatsuka, Increased mitotic phosphorylation of histone $\mathrm{H} 3$ attributable to AIM-1/Aurora-B overexpression contributes to chromosome number instability, Cancer Res. 62(2002)5168-77.

64. S. Dutertre, E. Hamard-Péron, J.Y. Cremet, Y. Thomas, C. Prigent, The absence of p53 aggravates polyploidy and centrosome number abnormality induced by Aurora-C overexpression. Cell Cycle. 4(2005)1783-7.

65. S. Hauf, R.W. Cole, S. LaTerra, C. Zimmer, G. Schnapp, R. Walter, A. Heckel, J. van Meel, C.L. Rieder, J.M. Peters, The small molecule Hesperadin reveals a role for Aurora $\mathrm{B}$ in correcting kinetochore-microtubule attachment and in maintaining the spindle assembly checkpoint, J Cell Biol. 161(2003)281-94.

66. F.J. Giles, J. Cortes, D. Jones, D. Bergstrom, H. Kantarjian, S.J. Freedman, MK-0457, a novel kinase inhibitor, is active in patients with chronic myeloid leukemia or acute lymphocytic leukemia with the T315I BCR-ABL mutation, Blood. 109(2007)500-2.

67. E. H. Rubin, G. I. Shapiro, M. N. Stein, P. Watson, D. Bergstrom, A. Xiao, J. B. Clark, S. J. Freedman, J. P. Eder, A phase 1 clinical and pharmacokinetic trial of the aurora kinae inhibitor MK-0457 in cancer patients, [abstract 3009]. Proc Am Soc Clin Oncol. 24(2006)123s.

68. J. H. Schellens, D. Boss, P. O. Witteveen, A. Zandvliet, J. H. Beijnen, M. Voogel-Fuchs, 
C. Morris, D. Wilson, E. E. Voest, Phase 1 and pharmacological study of the novel aurora kinase inhibitor AZD1152 [abstract 3008], Proc Am Soc Clin Oncol. 24(2006)123s.

69. M. Modugno, E. Casale, C. Soncini, P. Rosettani, R. Colombo, R. Lupi, L. Rusconi, D. Fancelli, P. Carpinelli, A.D. Cameron, et al, Crystal structure of the T315I Abl mutant in complex with the aurora kinases inhibitor PHA-739358, Cancer Res. 67(2007)7987-90. 


\section{Figure Legends.}

Figure 1. Function of Aurora A kinase. (A), Aurora A phosphorylates transforming acid coiled-coil (TACC) proteins. The activated TACC and Aurora A are recruited to the centrosome and form a complex with microtubule-associated proteins such as Msps/XMAP215, centrosomin, and $\gamma$-tubulin, leading to growth of microtubules, which consequently promotes maturation of the centrosome. (B), Aurora A phosphorylates Ajuba. The phosphorylated form of Ajuba binds to Aurora A, leading to activation of Aurora A at late G2 phase. Aurora A and Ajuba consequently activate cyclin B1/CDK1 complex, resulting in commitment of cells to mitosis.

Figure 2. Function of Aurora B kinase. (A), Aurora B is activated by autophosphorylation after association with the passenger complex, which consists of inner centrosome protein (INCENP), survivin, and borealin. Activated Aurora B recruits pavarotti to the central spindle region during anaphase. Pavarotti is essential for establishment of the central spindle. (B), CENP-A is first phosphorylated on Ser7 by Aurora A during prophase, which recruits Aurora B to the inner centromere. Aurora B then maintains phosphorylation of CENP-A on Ser7 from late prophase through metaphase and regulates kinetochore functions. 
Table 1. Aurora kinase inhibitors.

\begin{tabular}{|c|c|c|c|c|c|}
\hline Aurora kinase inhibitor & Chemical class & Aurora A IC50 & Aurora B IC50 & Other targets & References \\
\hline $\begin{array}{l}\text { Hesperadin } \\
\text { (Boehringer Ingelheim) }\end{array}$ & Indolinone & Not available & $250 \mathrm{nM}$ & Not available & 65 \\
\hline $\begin{array}{l}\text { ZM447439 } \\
\text { (AstraZeneca) }\end{array}$ & Quinazoline derivative & $110 \mathrm{nM}$ & $130 \mathrm{nM}$ & $\begin{array}{l}\text { LCK } 0.88 \mu M \\
\text { SRC } 1.03 \mu M \\
\end{array}$ & 51,67 \\
\hline $\begin{array}{l}\text { MK0457 } \\
\text { (Merck) } \\
\end{array}$ & 4,6 Diaminopyrimidine & $0.6 \mathrm{nM}$ & $18 \mathrm{nM}$ & FLT3 30 nM & 19 \\
\hline $\begin{array}{l}\text { AZD1152 } \\
\text { (AstraZeneca) }\end{array}$ & Quinazoline derivative & $1368 \mathrm{nM}$ & $0.37 \mathrm{nM}$ & Not available & $20-22,68$ \\
\hline $\begin{array}{l}\text { MLN8054 } \\
\text { (Millennium) }\end{array}$ & Benzazepine derivative & $4 \mathrm{nM}$ & $172 \mathrm{nM}$ & $\begin{array}{l}\text { CHK2 } 28 \mu \mathrm{M} \\
\text { PLK } 53 \mu \mathrm{M} \\
\end{array}$ & 23 \\
\hline $\begin{array}{l}\text { PHA-739358 } \\
\text { (Nerviano Medical Sciences) }\end{array}$ & 3-aminopyrazole derivative & $13 \mathrm{nM}$ & $79 \mathrm{nM}$ & ABL $25 \mathrm{nM}$ & 24 \\
\hline
\end{tabular}




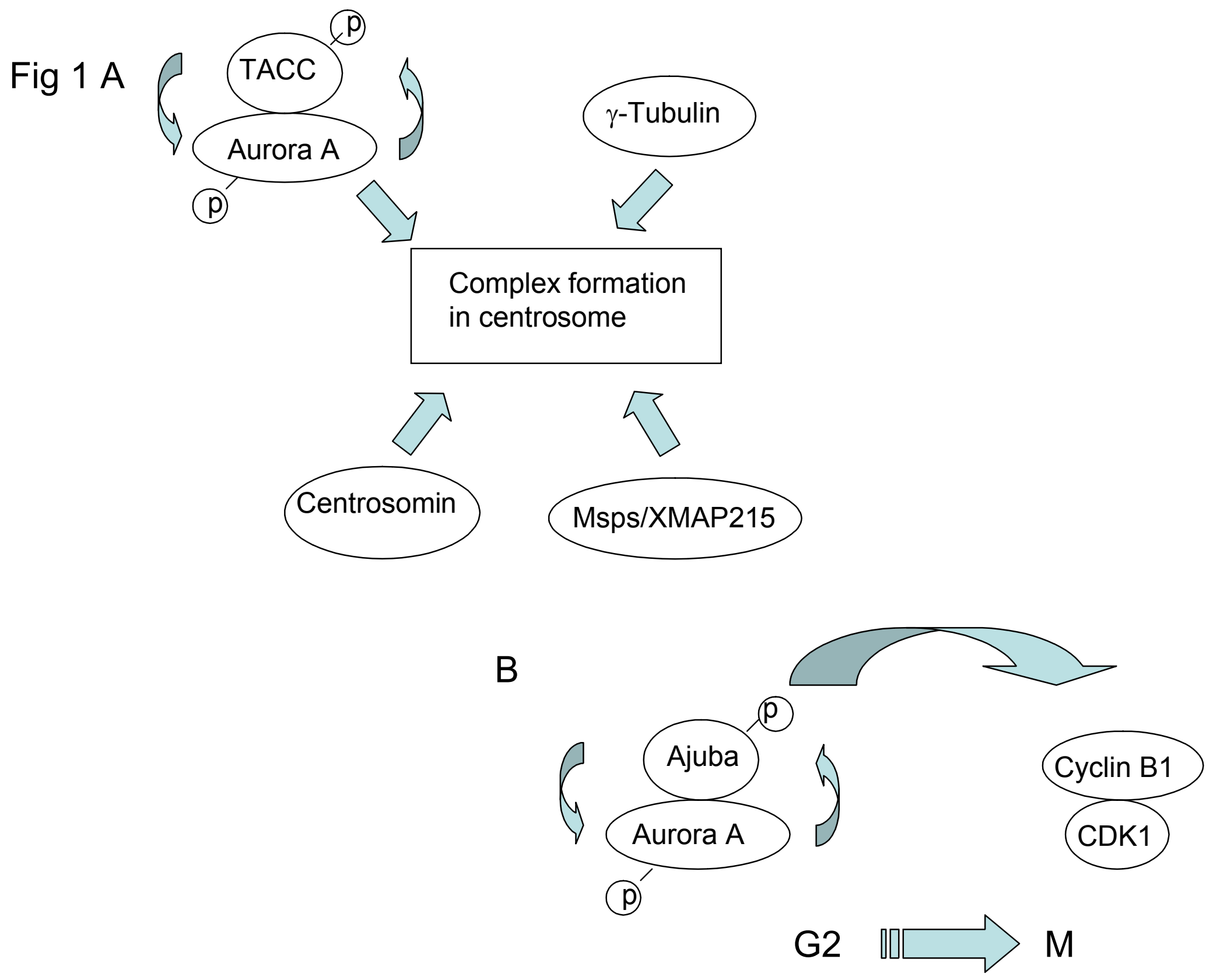


Fig 2A

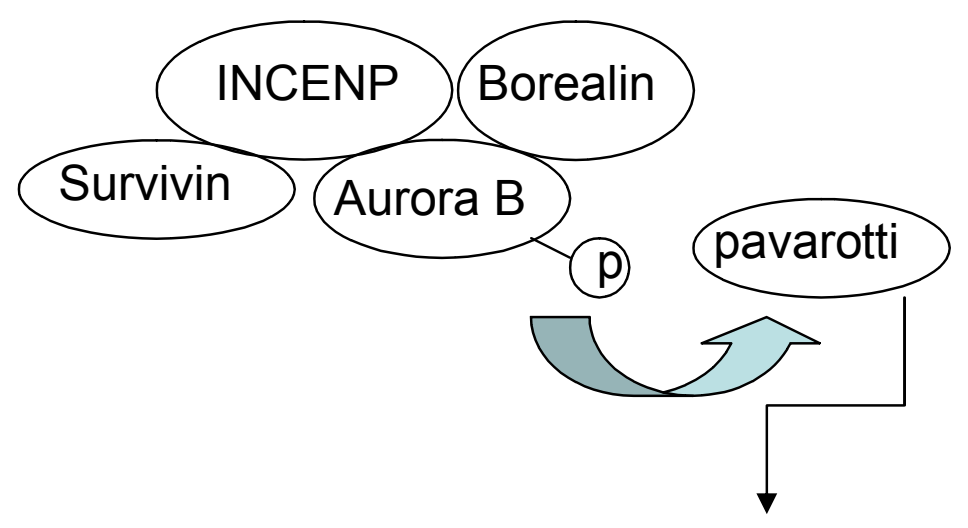

Central spindle region

Anaphase

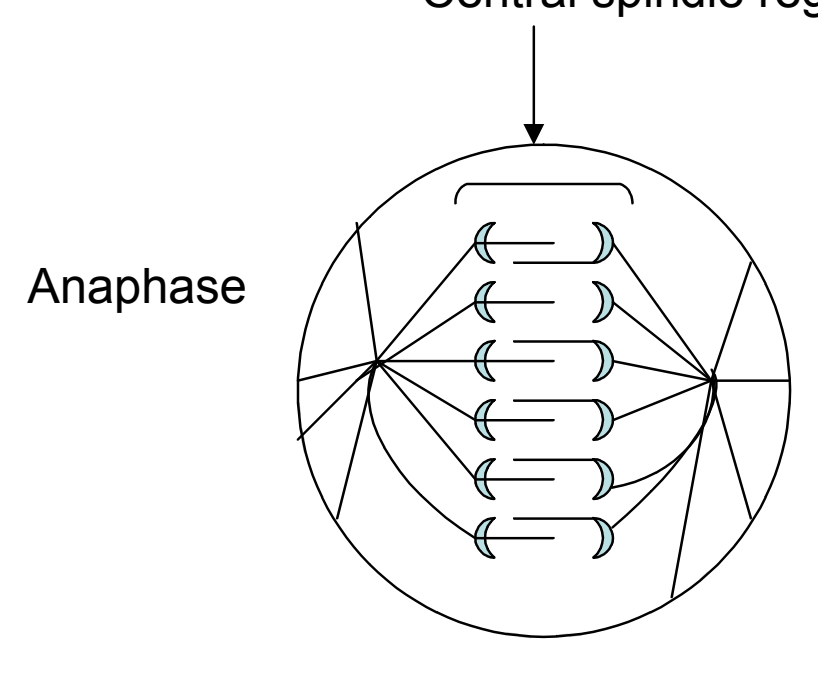

B




Recommended reviewer: Prof. Hideyuki Saya

Division of Gene Regulation, Institute of Advanced Medical research, Keio University School of Medicine, 35 Shinanomachi, Shinjuku-ku, Tokyo 160-8582, Japan

hsaya@gpo.kumamoto-u.ac.jp 